\begin{tabular}{|c|c|c|}
\hline $\begin{array}{l}\text { JURNALPENELITIAN KEPERAWATAN } \\
\text { MEDIK }\end{array}$ & VOL. 1 NO. 2 & $\begin{array}{c}\text { EDITION: NOVEMBER } 2018- \\
\text { APRIL } 2019\end{array}$ \\
\hline & http://ejournal.delihusada.ac.id/index.php/JPKM & \\
\hline RECEIVED: 20 JANUARI 2019 & REVISED: 24 MARET 2019 & ACCEPTED: 28 APRIL 2019 \\
\hline
\end{tabular}

\title{
HUBUNGAN PENDIDIKAN BERKELANJUTAN DENGAN KOMPETENSI SISWA PERAWAT DI INSTITUSI KESEHATAN DELI HUSADA DELITUA TAHUN 2019
}

\author{
Tedty Rohaya Tinambunan, Anita Theresia Lumban Gaol
}

Institut Kesehatan Deli Husada Delitua, Jl. Besar No.77 Deli Tua Kab. Deli Serdang

E-mail :tedtyrohayatinambunan15@gmail.com

\begin{abstract}
"Sustainable nursing education is professional development that includes a variety of activities carried out by someone in his capacity as a nurse practitioner, in order to maintain and enhance their professionalism as nurses according to established competency standards. The purpose of this study is to find out the relationship between continuing education and nurse competency at inHealth Institute of Deli Husada DelituaThis type of research is an analytical survey with a cross sectional approach. The technique used in sampling is total sampling, namely the total sampling technique with a sample size of 48. The result of this study indicate that there is a continuing educational relationship with nurse.The conclusion of this study is the relationship between continuing education and the competence of nurses at inHealth Institute of Deli Husada Delitua. Advice that can be given is that the institution continues to provide and include nurses in continuing education to assist nurses in developing their competence".
\end{abstract}

Key words: continuing education, competence, nurse, Institution

\section{Pendahuluan}

Pendidikan merupakan salah satu cara orang-orang dalam menjunjung tinggi nilai luhur untuk menjadikan seseorang menjadi kreatif serta dapat mengembangkan lebih luas potensi sesuai dengan kemampuannya. Dalam UU 38 tahun 2014 pasal 53, menjelaskan bahwa Pendidikan Berkelanjutan Keperawatan merupakan pendidikan formal melalui peningkatan jenjang pendidikan diharapkan perawat mampu meningkatkan kemampuannya seperti pengetahuan, keterampilan serta sikap. Dari meningkatnya kemampuan seorang perawat maka perawat mampu memberikan pelayanan keperawatan secara profesional dan juga pendidikan non formal misalnya seminar, workshop dan juga pelatihan dan diharapkan semua yang dilakukan dapat memenuhi kebutuhan dan mengembangkan kemampuan dan keterampilan yang dimiliki oleh perawat" (Ahmad Fadholi, 2018).

Pendidikan berkelanjutan dapat diperoleh melalui keanggotaan dan partisipasi dalam suatu perkumpulan profesi, kehadiran dalam berbagai konferensi, seminar dan kursus yang diadakan dalam suatu universitas, program pelatihan yang dilaksanakan oleh organisasi (in house training programs), serta partisipasi dalam proyek penelitian". Dari kutipan yang telah dijelaskan sebelumnya oleh Hiro Tugiman (2002: 31) dikemukakan bahwa pendidikan berkelanjutan bias dilakukan oleh seorang auditor dengan cara mengikuti seminar, kursus, partisipasi dalam suatu perkumpulan profesi, dan sebagainya.

Menurut Badan Pengembangan dan Pemberdayaan Sumber Daya Manusia Kesehatan (BPPSDMK, 2016) menyatakan bahwa, di Indonesia terdapat sebanyak 296.876 orang tenaga keperawatan, 


\begin{tabular}{|c|c|c|}
\hline $\begin{array}{l}\text { JURNALPENELITIAN KEPERAWATAN } \\
\text { MEDIK }\end{array}$ & VOL. 1 NO. 2 & $\begin{array}{l}\text { EDITION: NOVEMBER 2018- } \\
\text { APRIL } 2019\end{array}$ \\
\hline & http://ejournal.delihusada.ac.id/index.php/JPKM & \\
\hline RECEIVED: 20 JANUARI 2019 & REVISED: 24 MARET 2019 & ACCEPTED: 28 APRIL 2019 \\
\hline
\end{tabular}

Sumatera Utara berkisar 16.404 orang dan Kota Medan 5.098 orang (Dinas Kesehatan Provinsi Sumatera Utara, 2018). Sedangkan menurut jenjang pendidikan SPK jumlah perawat sebanyak 15.347 orang, sedangkan lulusan Diploma dan Sarjana Keperawatan tanpa Ners sebanyak 32.189 orang (Infodatin, 2016).

Menurut Jefferies, dkk pada tahun 2012 didalam buku Pengembangan keprofesian Berkelanjutan (PKB) menyatakan bahwa dalam peningkatan pengetahuan didalam dokumentasi keperawatan memerlukan pelatihan. Pada tahun 2014 pada penelitian yang dilakukan Lewis, dkk menyatakan bahwa dalam pengembangan kemajuan profesi dan tanggung jawab sangat diperlukan pendidikan yang berkelanjutan agar terjadi peningkatan mutu pelayan rumah sakit. Sehingga penyelenggara perguruan tinggi keperawatan harus memenuhi standar nasional pendidikan keperawatan yang mengacu pada standar nasional pendidikan tinggi yang disusun secara bersama oleh kementerian bidang kesehatan, bidang pendidikan, asosiasi institusi pendidikan dan organisasi profesi keperawatan yang ditetapkan oleh menteri yang menyelenggarakan urusan pemerintah di bidang pendidikan (UU No. 38 tahun 2014 tentang keperawatan pasal 11).

Menurut penelitian Siswanto, dkk dalam penelitiannya yang berjudul hubungan pendidikan berkelanjutan dan pelatihan kompetensi dengan kinerja perawat di ruang model praktik perawat professional berpendapat bahwa terdapat hubungan antara pendididikan berkelanjutan dengan kinerja perawat" (Siswanto, 2015). Sedangkan penelitian Rahmad wahyudi dengan judul hubungan implementasi kebijakan praktek profesional, pendidikan berkelanjutan, pengembangan profesi ilmu pengetahuan, dan pengabdian masyarakat dalam upaya perpanjangan registrasi perawat dengan peningkatan kompetensi perawat PPNI Kabupaten Kota Bangkalan menunjukkan tidak ada hubungan pendidikan berkelanjutan dengan kompetansi perawat.

Berdasarkan wawancara pemula ataupun wawancara dasaryang peneliti lakukan kepada Kepala Bidang Keperawatan bulan Oktober 2018 di Institut Kesehatan Deli Husada Delitua diperoleh populasi sejumlah 48 Ners yang sudah memiliki STR.

Sesuai dengan pemberlakuan Ristekdikti tahun 2014 yang mewajibkan perawat mengikuti uji kompetensi, maka dinyatakan 31 orang tidak mengikuti uji kompetensi, 17 orang harus mengikuti dan 10 orang dinyatakan lulus dan 7 orang tidak lulus. Sedangkan pendidikan berkelanjutan yang sudah dimiliki perawat melalui pelatihan adalah BTCLS sebanyak 24 orang eksternal, manajemen bangsal 14 orang eksternal, pelatihan IPCN 2 orang eksternal, pelatihan kredensial perawat 4 orang eksternal. Hasil angket kepuasan pasien yang mendukung mutu pelayanan pada Triwulan III (JuliSeptember) tahun 2018 diperoleh 90,50\% puas terhadap pelayanan siswa perawat Institut Kesehatan Deli Husada Delitua. Berdasarkan latar belakang tersebut peneliti tertarik untuk melakukan penelitian mengenai Apakah ada Hubungan Pendidikan Berkelanjutan Dengan kompetensi siswa perawat Di Institut Kesehatan Deli Husada Delitua Tahun 2019.

\section{METODE}

Penelitian yang dipilih peneliti dengan menggunakan survey analitik. Dalam penelitian dengan judul Hubungan Pendidikan Berkelanjutan Dengan kompetensi siswa perawat Di Institut Kesehatan Deli Husada Delitua Tahun 2019 peneliti hanya melakukan penelitian dengan sekali waktu dan hanya mengambil variable dependen dan variable independennya. Karena sebab itu, peneliti menggunakan metode Cross Sectional dalam melakukan penelitian ini. Sedangkan populasi yang dipilih dari penelitian ini adalah seluruh Ners Institut Kesehatan Deli Husada Delitua 


\begin{tabular}{|c|c|c|}
\hline $\begin{array}{l}\text { JURNALPENELITIAN KEPERAWATAN } \\
\text { MEDIK }\end{array}$ & VOL. 1 NO. 2 & $\begin{array}{l}\text { EDITION: NOVEMBER } 2018- \\
\text { APRIL } 2019\end{array}$ \\
\hline & http://ejournal.delihusada.ac.id/index.php/JPKM & \\
\hline RECEIVED: 20 JANUARI 2019 & REVISED: 24 MARET 2019 & ACCEPTED: 28 APRIL 2019 \\
\hline
\end{tabular}

tersebut dengan jumlah 48 orang. Dan sampel yang diambil peneliti dengan menggunakan total sampling yaitu seluruh populasi yang berjumlah 48 orang (Sugiono, 2015).

Dalam melihat atau untuk mengetahui apakah ada Hubungan Pendidikan Berkelanjutan Dengan kompetensi siswa perawat $\mathrm{Di}$ Institut Deli Husada Delitua Tahun 2019, peneliti menggunakan uji ChiSquare dengan $a=0,05$ (Sugiono, 2015).

Data-data diambil dari responden yaitu siswa perawat di Institut Kesehatan Deli Husada Delitua Tahun 2019 dengan menggunakan kuesioner yang telah dibagikan kepada responden tersebut.

\section{HASIL DAN PEMBAHASAN}

Tabel 1. Karakteristik Responden

\begin{tabular}{|c|c|c|c|}
\hline $\mathrm{No}$ & $\begin{array}{l}\text { KarakteristikRe } \\
\text { sponden }\end{array}$ & $\mathrm{F}$ & $(\%)$ \\
\hline a & Jenis kelamin & & \\
\hline 1 & Laki-laki & 5 & $10,4 \%$ \\
\hline \multirow[t]{2}{*}{2} & Perempuan & 43 & $89,6 \%$ \\
\hline & Jumlah & 48 & 100,0 \\
\hline$B$ & Umur & & \\
\hline 1 & 21-35 Tahun & 17 & $35,4 \%$ \\
\hline 2 & 36-45 Tahun & 30 & $62,5 \%$ \\
\hline 3 & $\geq 46$ Tahun & 1 & 2,1 \\
\hline \multicolumn{2}{|c|}{ Jumlah } & 48 & 100,0 \\
\hline C & Masa Kerja: & & \\
\hline 1 & 1-5 Tahun & 10 & $20,8 \%$ \\
\hline 2 & 6-15 Tahun & 22 & $45,8 \%$ \\
\hline 3 & 16-20 Tahun & 10 & $20,8 \%$ \\
\hline 4 & $\geq 20$ Tahun & 6 & $12,5 \%$ \\
\hline \multicolumn{2}{|c|}{ Jumlah } & 48 & 100,0 \\
\hline
\end{tabular}

Berdasarkan tabel 1 dapat diketahui bahwa responden tertinggi pada penelitian ini yaitu pada kategori perempuan sebanyak 43 orang $(89,6 \%)$, responden tertinggi pada kategori umur yaitu pada umur 36-45 tahun sebanyak 30 orang $(62,5 \%)$, dan responden tertinggi pada kategori masa kerja yaitu pada 6-15 tahun sebanyak 22 orang (20,8\%).

Tabel 2. Frekuensi tentang Pendidikan Berkelanjutan

\begin{tabular}{clll}
\hline No & $\begin{array}{l}\text { Pendidikan } \\
\text { Berkelanjutan }\end{array}$ & F & (\%) \\
\hline 1 & Baik & 44 & 91,7 \\
\hline 2 & Kurang baik & 4 & 8,33 \\
\hline Jumlah & & 48 & 100,0 \\
\hline
\end{tabular}

Berdasarkan Tabel 2 dapat dilihat kalau responden tertinggi pada penelitian ini yaitu pada kategori baik sebanyak 44 orang $(91,7 \%)$ dan responden terendah pada penelitian ini yaitu pada kategori kurang baik sebanyak 4 orang $(8,33 \%)$.

Tabel 3 Distribusi Frekuensi Kompetensi Perawat

\begin{tabular}{llll}
\hline No & $\begin{array}{l}\text { Kompetensi } \\
\text { Perawat }\end{array}$ & F & $(\%)$ \\
\hline 1 & Kompeten & 47 & 97,9 \\
2 & Tidakkompeten & 1 & 2,01 \\
\hline Jumlah & 48 & 100,0 \\
\hline
\end{tabular}

Berdasarkan Tabel 3 dapat dilihat kalau responden tertinggi pada penelitian ini yaitu pada kategori Kompeten sebanyak 47 orang $(97,9 \%)$ dan responden terendah pada penelitian ini yaitu pada kategori tidak kompeten sebanyak 1 orang (2,01\%).

Tabel 4 Hubungan Pendidikan Berkelanjut dengan Kompetensi siswa Perawat di Institut Kesehatan Deli Husada Delitua Tahun 2019

\begin{tabular}{|c|c|c|c|c|c|c|c|c|c|}
\hline \multirow{3}{*}{ No } & \multirow{3}{*}{$\begin{array}{l}\text { Pendidikan } \\
\text { Berkelanjutan }\end{array}$} & \multicolumn{8}{|c|}{ Kompetensi siswa Perawat } \\
\hline & & \multicolumn{2}{|c|}{ Kompeten } & \multicolumn{2}{|c|}{$\begin{array}{l}\text { Tidak } \\
\text { Kompeten }\end{array}$} & \multicolumn{2}{|c|}{ Jumlah } & \multirow[t]{2}{*}{ PR } & \multirow[t]{2}{*}{ p-value } \\
\hline & & $\mathrm{F}$ & $\%$ & $f$ & $\%$ & $\mathrm{~F}$ & $\%$ & & \\
\hline 1. & Baik & 44 & 91,7 & 0 & 0 & 44 & 91,7 & 0,750 & 0,001 \\
\hline \multirow[t]{2}{*}{2.} & Kurang baik & 3 & 6,25 & 1 & 2,08 & 4 & 8,33 & & \\
\hline & Jumlah & 47 & 97,91 & 1 & 2,08 & 48 & 100,0 & & \\
\hline
\end{tabular}




\begin{tabular}{|c|c|c|}
\hline $\begin{array}{l}\text { JURNALPENELITIAN KEPERAWATAN } \\
\text { MEDIK }\end{array}$ & VOL. 1 NO. 2 & $\begin{array}{l}\text { EDITION: NOVEMBER 2018- } \\
\text { APRIL } 2019\end{array}$ \\
\hline & http://ejournal.delihusada.ac.id/index.php/JPKM & \\
\hline RECEIVED: 20 JANUARI 2019 & REVISED: 24 MARET 2019 & ACCEPTED: 28 APRIL 2019 \\
\hline
\end{tabular}

Hasil uji Chi-square menunjukkan bahwa ada hubungan antara pendidikan berkelanjutan dengan kompetensi siswa perawat Institut Kesehatan Deli Husada Delitua Tahun 2019.

\section{PEMBAHASAN}

Hasil penelitian yang sudah dilakukan peneliti menunjukkan ada hubungan antara pendidikan berkelanjutan dengan kompetensi siswa perawat di Institut Kesehatan Deli Husada Delitua Tahun 2019 dengan nilai pValue $=0,001<a=0,05$ yang dilihat peneliti dari hasil statistik yang sudah dilakukan dengan menggunakan uji Chi-Square.

Hasil penelitian yang telah dilakukan peneliti bahwa penelitian ini sejalan dengan penelitian yang telah dilakukan oleh Faculty of Nursing Universitas Pelita Harapan Tangerang dengan judul Hubungan Tingkat Pendidikan Perawat Dengan Kompetensi Perawat yang dilakukan dengan 105 responden. Dari penelitian yang dilakukan oleh Faculty of Nursing Universitas Pelita Harapan Tangerang menunjukkan bahwa adanya Hubungan Tingkat Pendidikan Perawat Dengan Kompetensi Perawat. Peneliti menyimpulkan bahwa, "penelitian ini berfokus kepada institusi kesehatan, rumah sakit, klinik dan praktek mandiri perawat sebaiknya mendukung perkembangan jenjang karir seorang perawat dalam peningkatan pendidikan yang sudah jelas terbukti sangat mendukung agar perawat lebih berkualitas dan teruji" (Faculty of Nursing Universitas Pelita Harapan Tangerang, 2012).

Hasil penelitian yang telah dilakukan peneliti bahwa penelitian ini sejalan dengan penelitian yang telah dilakukan oleh Jebul Seroso dengan judul penelitian Penataan Sistem Jenjang karir berdasarkan kompetensi perawat untuk meningkatkan kepuasan kerja dan kinerja perawat di rumah sakit. Peneliti menyimpulkan bahwa sistem jenjang karir perawat sangat berguna dalam meningkatkan kinerja dan profesionalisme dalam bidak perkerjaan perawat tersebut melalui peningkatan kompetensinya" (Jebul, 2010).

\section{KESIMPULAN}

\section{Kesimpulan}

Berdasarkan penelitian yang dilakukan peneliti bahwa dapat disimpulkan bahwa adanya hubungan antara pendidikan berkelanjutan dengan kompetensi perawat di Instalasi Rawat Inap Rumah Sakit TK II Putri Hijau Kesdam I/BB Medan Tahun 2019 dengan $\mathrm{p}$-Value $=0,001<\mathrm{a}=0,05$. Maka dari hasil penelitian yang didapat, peneliti beranggapan bahwa apabila institusi tetap menyediakan dan mengikut sertakan siswa perawat dalam pendidikan berkelanjutan maka hal tersebut membantu perawat dalam mengembangkan kompetensinya.

\section{Saran}

1. Bagi Perawat

Tetap ikut serta dalam pendidikan berkelanjutan agar perawat dapat mengembangkan kompetensi yang dimiliki sesuai dengan tuntutan yang ada di masyarakat dan profesi

2. Bagi Institut Kesehatan Deli Husada Deli Tua

Disarankan bagi Institut Kesehatan Deli Husada Deli Tua untuk menambah bahan bacaan mengenai pendidikan berkelanjutan dan kompetensi perawat.

3. Bagi Peneliti

Dapat menambah wawasan dalam penelitian dan sebagai bahan bacaan untuk studi penelitian selanjutnya.

\section{DAFTAR PUSTAKA}

Ahmad Fadholi, 2018, Rekomendasi Peningkatan Kualifikasi Dan Komptensi Perawat Rumah Sakit X Mojokerto Melalui Pendekatan Human Capital, MTPH Journal, Volume 2, No. 1

Info Datin (Pusat Data Dan Informasi Kementerian Kesehatan RI), 2016, 


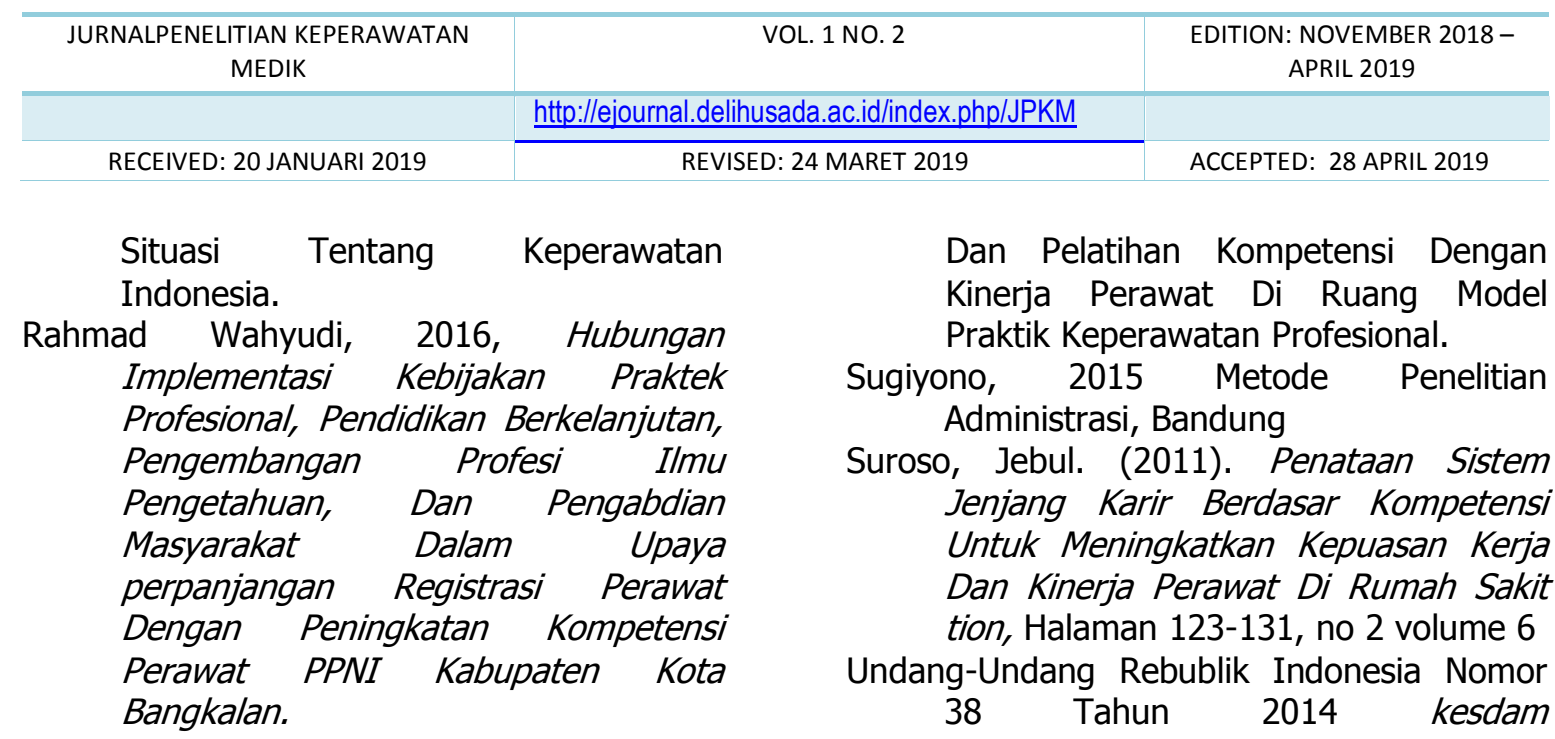

Siswanto, Tri Hartati, Agus Santoso, 2015, Hubungan Pendidikan Berkelanjutan 